\title{
(る) OPEN ACCESS \\ Cut-off value of serum homocysteine in relation to increase of coronary artery calcification
}

\author{
Susie Jung, ${ }^{1}$ Yu-Na Kim, ${ }^{1}$ Beom-Hee Choi, ${ }^{2}$ Nam-Seok Joo (i) ${ }^{3}$
}

${ }^{1}$ Department of Family Practice and Community Health, Ajou University School of Medicine, Suwon, South Korea

${ }^{2}$ Functional Medicine Clinic, GCIMED, Seoul, South Korea ${ }^{3}$ Department of Family Practice and Community Health, Ajou University Hospital, Suwon, Gyeonggido, South Korea

\section{Correspondence to} Dr Nam-Seok Joo, Department of Family Practice and Community Health, Ajou University School of Medicine, Suwon 164, Gyeonggi-do, South Korea; jchcmc@hanmail.net

Accepted 20 October 2020 Published Online First 4 November 2020
Check for updates

(C) American Federation for Medical Research 2021. Re-use permitted under CC BY-NC. No commercial re-use. Published by BMJ.

To cite: Jung S, Kim Y-N, ChoiB-H,etal.JlnvestigMed 2021;69:345-350.

\begin{abstract}
A recent study reported that coronary artery calcification (CAC) and serum homocysteine were well associated; however, no report is available for the cut-off value of serum homocysteine according to increase of coronary-artery calcification volume score (CVS). The data of 469 out of 777 subjects in 1 health promotion center located in Seoul were selected after exclusion of the missing data of serum homocysteine and CVS. CVS was categorized into 2 groups: CVS $=0$ and CVS $>0$. Serum homocysteine according to the CVS groups was compared, and the cut-off value of serum homocysteine according to the increase of CVS $(>0)$ was calculated using the receiver operating characteristic curve. Mean age was 54.5 years and the proportion of females was $22.2 \%$. Mean serum homocysteine concentration and CVS were $11.2 \mu \mathrm{mol} / \mathrm{L}$ and 50.4 , respectively. After adjustments for age and sex, serum homocysteine was associated with CVS ( $r=0.167$, $p=0.001$ ), and Log(Homocysteine) also showed a significant difference according to the CVS groups. The cut-off value of serum homocysteine according to the increase of CVS $(>0)$ was $9.45 \mu \mathrm{mol} / \mathrm{L}$ (area under the curve $=0.569(95 \% \mathrm{Cl} 0.512$ to 0.625$)$, $p=0.015)$. The cut-off value of serum homocysteine was $9.45 \mu \mathrm{mol} / \mathrm{L}$ according to the increase of coronary-artery CVS.
\end{abstract}

\section{INTRODUCTION}

Coronary artery calcification (CAC) in the asymptomatic population has been recognized as a marker for subclinical coronary atherosclerosis. ${ }^{1}$ The presence of calcification in the coronary artery suggests atherosclerosis, and the progression or severity of calcification is closely related to the total coronary plaque burden and clinical cardiac events. ${ }^{2-4}$ The prevalence and severity of CAC differ according to ethnicity, age, and comorbidities, such as diabetes or chronic kidney disease. ${ }^{5}$

In histopathologic studies, calcification is easily found in atherosclerotic plaques in coronary vessels, and unlike non-calcified plaques, calcified plaques are highly related to the level of homocysteine. ${ }^{6}$ Being a well-known independent risk factor for atherosclerotic vascular disease and cardiac mortality, ${ }^{7}$ a high level of homocysteine plays a role in the pathophysiology of developing calcified atherosclerosis. Although a positive correlation of the degree

\section{Significance of this study}

What is already known about this subject?

- Coronary artery calcification is closely related to the total coronary plaque burden and clinical cardiac events.

- Serum homocysteine is a marker of the vascular inflammation.

- Elevated serum homocysteine concentration is closely related with coronary artery calcification.

\section{What are the new findings?}

- Serum homocysteine is an important factor in relation with coronary artery calcification after adjusting for age and sex.

- Serum homocysteine showed a significant difference according to the coronary artery volume score (CVS) groups.

- The cut-off value of serum homocysteine was $9.45 \mu \mathrm{mol} / \mathrm{L}$ according to the increase of CVS.

How might these results change the focus of research or clinical practice?

- Subjects who have elevated serum homocysteine concentration should be considered to evaluate the coronary artery calcification.

- Elevated serum homocysteine concentration should be lowered for the prevention of coronary artery calcification.

- Long-term prospective clinical trial should be carried out to evaluate the effect of maintaining the lowered serum homocysteine on the development of coronary artery calcification.

of CAC according to the homocysteine level is recognized, ${ }^{8}$ no studies have been carried out to specify how homocysteine affects CAC.

For the elevation of homocysteine with vascular calcification and the possibility of its function as a predictor for CAC, CT is a useful tool for detecting macrocalcification of atherosclerotic plaques. ${ }^{9}$ The role of homocysteine in coronary artery plaque formation leading to CAC is being increasingly recognized, yet no study has revealed the cut-off value of homocysteine for the presence of CAC. Therefore, we tried to find the cut-off value for homocysteine 
regarding CAC using the coronary artery volume score (CVS) in a Korean asymptomatic population.

\section{METHODS}

\section{Data source and study subjects}

This was a cross-sectional study including Koreans who had not been diagnosed with cardiovascular diseases (CVD), such as cardiac arrest, coronary heart disease, stroke, and other definite diseases of cardiovascular origin. The 777 participants had undergone a medical check-up including a cardiac CT scan in a single health promotion center in Seoul, Republic of Korea, from January 2010 to December 2019. The medical check-up included all items in the Korean national health screening program, which contains a lifestyle assessment about exercise, nutrition, obesity, alcohol intake, smoking, measurement of automated blood pressure, height, weight, and blood sample for hemoglobin, fasting glucose, lipid panel, creatinine, estimated glomerular filtration rate, aspartate amino transferase, and alanine amino transferase. In addition, serum fasting insulin and homocysteine were analyzed. A total of 469 participants were included in the study after we excluded 308 participants who had not met the criteria (no data of CVS and serum homocysteine). All participants attended voluntarily without any reward and informed consent was obtained from all subjects.

\section{Anthropometric and laboratory data}

The data of each patient's medical history and lifestyle were recorded on self-administered questionnaires. Smoking status was answered either 'I am a current smokers' or 'I have never been a smoker'. Blood pressure was measured with an automated sphygmomanometer in a sitting position. Body measurements included height, weight, and waist circumference. Subjects' height and weight were measured by an automated digital height and weight scale. Body mass index (BMI) $\left(\mathrm{kg} / \mathrm{m}^{2}\right)$ was calculated as one's weight (in kilograms) divided by the square of one's height (in meters). Waist circumference was measured mid-way with a tapeline from just below the bottom rib to the superior border of the iliac crest while in standing position. Fasting blood samples were obtained from each subject in the morning. They were stored at $4^{\circ} \mathrm{C}$, analyzed within 1 day of sampling, and then used for assessing serum glucose, insulin, lipid panels, liver enzymes, and homocysteine. Serum homocysteine was analyzed by a fluorescence polarization immunoassay with IMx Analyzers (Axsym Abbott, Abbott Park, Illinois, USA).

\section{Measurement of coronary calcification}

We have gathered the coronary-artery calcification volume score (CVS) data from January 2010 to December 2019, which data were from the health check-up of general population in 1 health promotion center. We only gathered all checked CVS data during the period followed by the routine manual and CVS was calculated automatically after CT scan. The cardiac CT scan is a 64-slice multiple detector computed tomography (MDCT) scanner (GE LightSpeed VCT; GE Imatron, San Francisco, California, USA), and scan parameters were $3 \mathrm{~mm}$ slice thickness, $120 \mathrm{kV}$ tube voltage, and $110 \mathrm{mAs}$ tube current. We used a standard definition of coronary-artery CVS, that is, a hyperattenuating

\begin{tabular}{lc}
\hline \multicolumn{1}{l}{ Table 1} & General characteristics of study subjects $(\mathrm{n}=469)$ \\
\hline Values & Mean (SD) \\
\hline $\mathrm{n}(\%$ of female) & $104(22.2)$ \\
\hline Age $(\mathrm{y})$ & $54.5(9.7)$ \\
\hline BMl $\left(\mathrm{kg} / \mathrm{m}^{2}\right)$ & $24.5(2.9)$ \\
\hline Waist circumference $(\mathrm{cm})$ & $87.5(8.4)$ \\
\hline Glucose $(\mathrm{mg} / \mathrm{dL})$ & $91.3(10.6)$ \\
\hline Total cholesterol $(\mathrm{mg} / \mathrm{dL})$ & $209.2(35.8)$ \\
\hline Triglyceride $(\mathrm{mg} / \mathrm{dL})$ & $143.8(86.7)$ \\
\hline HDL-cholesterol $(\mathrm{mg} / \mathrm{dL})$ & $51.8(13.3)$ \\
\hline LDL-cholesterol $(\mathrm{mg} / \mathrm{dL})$ & $131.3(32.2)$ \\
\hline AST $(\mathrm{mg} / \mathrm{dL})$ & $26.4(9.1)$ \\
\hline ALT $(\mathrm{mg} / \mathrm{dL})$ & $26.3(14.6)$ \\
\hline Homocysteine $(\mu \mathrm{mol} / \mathrm{L})$ & $11.2(4.4)$ \\
\hline CVS & $50.4(91.8)$ \\
\hline Current smoking, $\mathrm{n}(\%)$ & $158(34.0)$ \\
\hline Hypertension, $\mathrm{n}(\%)$ & $157(34.0)$ \\
\hline Type 2 diabetes, $\mathrm{n}(\%)$ & $0(0 \%)$ \\
\hline
\end{tabular}

Values represent mean (SD) by descriptive method.

ALT, alanine amino transferase; AST, aspartate amino transferase; BMI, body mass index; CVS, calcification volume score; HDL, high-density lipoprotein;

LDL, low-density lipoprotein.

lesion in the coronary artery that is more than 3 pixels in size and more than 130 Hounsfield units.

\section{Data management and statistical analysis}

We represented all data results with mean and SD values by a descriptive method and used a $\chi^{2}$ test to evaluate the prevalence of hypertension, diabetes, and smoking status. After age and sex adjustment, we used partial correlation to evaluate the relationship between CVS and the other metabolic parameters, including serum homocysteine. Serum homocysteine showed skewed pattern, so the difference of $\log ($ Homocysteine) between CAC groups $(\mathrm{CVS}=0$ vs CVS $>0$ ) was compared by independent t-test and a general linear model (analysis of covariance test) after adjusting for age, smoking, and hypertension. Finally, we calculated the cut-off value for serum homocysteine according to increase in coronary-artery CVS (CVS $>0$ ), as shown in the receiver operating characteristic (ROC) curve. A p value $<0.05$ was considered statistically significant. We did complex sample analysis with SPSS V.25.0 (SPSS).

\section{RESULTS}

General characteristics of study subjects are presented in table 1 . The mean age was 54.5 years old, and the mean serum homocysteine level was $11.2 \mu \mathrm{mol} / \mathrm{L}$. Of the 469 subjects, 104 were female, and 158 were current smokers. There were no participants with diabetes in this study. Neither low-density lipoprotein cholesterol (LDL-C) nor systolic or diastolic blood pressure was correlated with coronary-artery CVS increase. Only homocysteine was being significantly correlated with CVS increase $(r=0.167$, $\mathrm{p}<0.001$ ) after age and sex adjustments (table 2, figure 1). The mean value of serum homocysteine concentration of the CVS $>0$ group was $18.17 \mu \mathrm{mol} / \mathrm{L}$, which was higher than that of the CVS $=0$ group $(10.18 \mu \mathrm{mol} / \mathrm{L})$. After the $\log$ transformation, the $\log ($ Homocysteine) value was 
Table 2 Partial correlation of coronary-artery calcification volume score (CVS) and other factors after age and sex adjustments

\begin{tabular}{lcl}
\hline Values & $\mathrm{r}$ & P value \\
\hline Body mass index $\left(\mathrm{kg} / \mathrm{m}^{2}\right)$ & 0.041 & 0.432 \\
Waist circumference $(\mathrm{cm})$ & 0.040 & 0.439 \\
Systolic blood pressure $(\mathrm{mm} \mathrm{Hg})$ & 0.012 & 0.177 \\
\hline Diastolic blood pressure $(\mathrm{mm} \mathrm{Hg})$ & 0.027 & 0.607 \\
Fasting glucose $(\mathrm{mg} / \mathrm{dL})$ & 0.070 & 0.173 \\
\hline Insulin $(\mu \mathrm{lU} / \mathrm{mL})$ & -0.017 & 0.736 \\
\hline AST $(\mathrm{mg} / \mathrm{dL})$ & -0.003 & 0.954 \\
\hline ALT $(\mathrm{mg} / \mathrm{dL})$ & 0.033 & 0.526 \\
\hline Total cholesterol $(\mathrm{mg} / \mathrm{dL})$ & 0.054 & 0.295 \\
\hline Triglyceride $(\mathrm{mg} / \mathrm{dL})$ & 0.034 & 0.507 \\
HDL $(\mathrm{mg} / \mathrm{dL})$ & 0.011 & 0.831 \\
\hline LDL $(\mathrm{mg} / \mathrm{dL})$ & 0.034 & 0.505 \\
Homocysteine $(\mu \mathrm{mol} / \mathrm{L})$ & 0.167 & 0.001 \\
\hline
\end{tabular}

Values represent partial correlation coefficient.

ALT, alanine amino transferase; AST, aspartate amino transferase; HDL, highdensity lipoprotein; LDL, low-density lipoprotein.

significantly different between the 2 groups, and the higher CVS group (CVS $>0$ ) showed significantly higher value than the normal CVS group (CVS=0), even after age, smoking, and hypertension adjustments (table 3 ). Figure 2 shows the ROC curve and cut-off value of the serum homocysteine for the presence of CAC (CVS $>0)$. The area under the curve (AUC) was 0.569 (95\% CI 0.512 to 0.625$)$. There were no points on the curve that went below the diagonal line, and the results achieved statistical significance $(p=0.015)$. The arrow on the ROC curve indicates the exact cut-off value of serum homocysteine according to the increase in coronary-artery CVS (CVS $>0$ ), and the cut-off value was 9.45 $\mu \mathrm{mol} / \mathrm{L}$ (table 4).

\section{DISCUSSION}

In this cross-sectional study, serum homocysteine was an independent factor for the increase of coronary-artery CVS,
Table 3 Serum homocysteine concentration according to coronary-artery calcification volume score (CVS)

\begin{tabular}{lllll}
\hline Value & CVS $=0$ & CVS $>0$ & P value & P value $^{*}$ \\
\hline Log (homocysteine) & $2.32(0.03)$ & $2.39(0.02)$ & 0.028 & 0.035 \\
\hline
\end{tabular}

Values represent mean (SE) serum homocysteine according to the CVS by independent $\mathrm{t}$-test after log transformation of serum homocysteine before adjustment ( $p$ value).

${ }^{*} \mathrm{P}<0.05$ by general linear model after age, smoking, and hypertension adjustments.

and its correlation remained significant even after adjustments for the risk factors of coronary artery disease, such as age, smoking, and hypertension. In addition, the cut-off value of serum homocysteine was $9.45 \mu \mathrm{mol} / \mathrm{L}$ in relation to the presence of the CAC.

CAC has been used as a marker of coronary atherosclerosis and is associated with major cardiovascular events and mortality. ${ }^{10} \mathrm{CAC}$ can be found in a broad spectrum of cardiovascular states, from severe CVD to asymptomatic early diagnosed coronary disease. ${ }^{11}$ Presence of CAC was positively associated with CVD, unlike absence of CAC, and increasing CAC leads to greater cardiac events and all-cause mortality. Furthermore, the degree of CAC and its progression is correlated with coronary vascular disease events and mortality. ${ }^{12}$ Coronary atherosclerotic plaques consist of fatty substance, LDL-C, inflammatory cells, smooth muscle cells (SMC), connective tissue, fibrin, thrombi, and deposits of calcium phosphate. CAC initially begins as microcalcification, which is a small aggregation of extracellular matrix vesicles (EV) from vascular SMCs (vSMC) or macrophages in the intimal lipid core, and grows into a larger calcified plaque by accumulating and aggregating $\mathrm{EV}$, which can be seen as a form of macrocalcification or calcium sheet. ${ }^{13-15}$ A cardiac CT scan cannot detect microcalcification, because of its spatial resolution and modality. ${ }^{10}$ However, it is a very effective tool for finding out the coronary plaque burden or coronary inflammation beyond the traditional Framingham

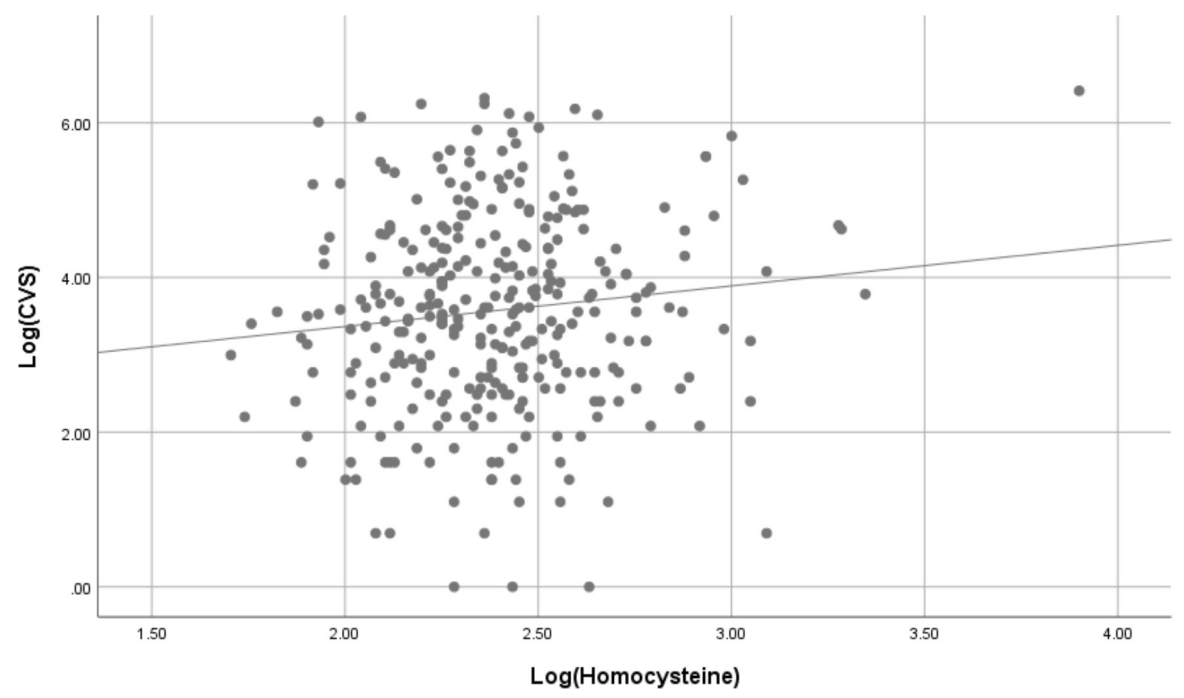

Figure 1 Correlation of serum homocysteine and coronary-artery calcification volume score (CVS) after log transformation ( $r=0.167$, $\mathrm{p}=0.001$ ). 


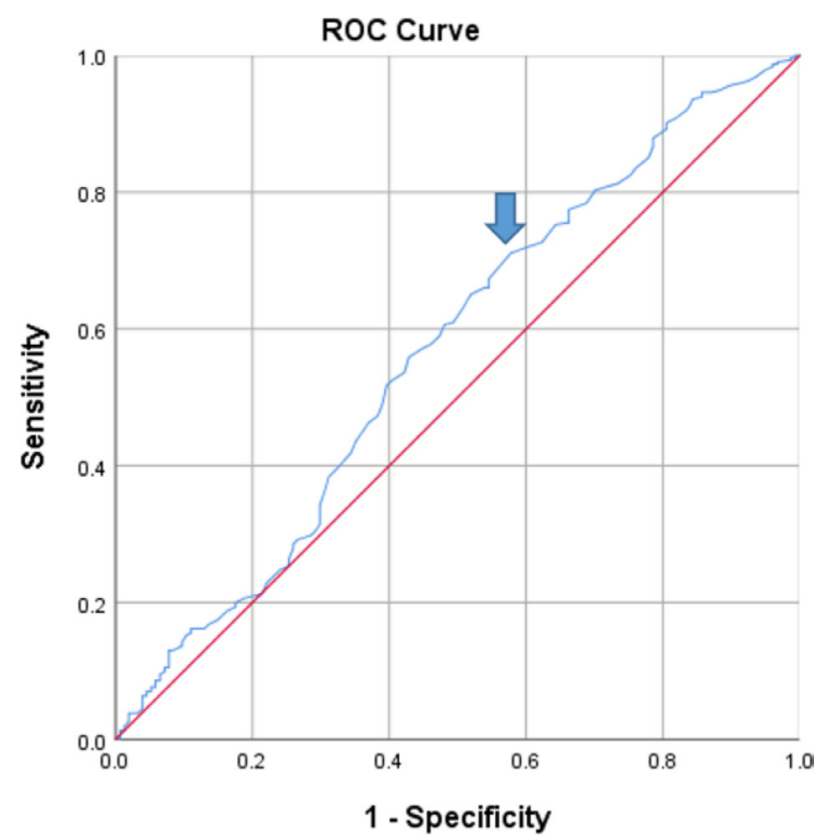

Figure 2 The cut-off value of serum homocysteine according to increase of coronary-artery calcification volume score. ROC, receiver operating characteristic.

risk score ${ }^{16}$ and it is used as a marker for cardiovascular events. ${ }^{1}$ Therefore, the presence of a coronary artery calcium volume score $(\mathrm{CVS}>0)$ means the presence of ongoing vascular inflammation leading to calcification and thus to atherosclerotic plaque formation in coronary arteries. Vascular calcification is a very active and dynamic process under tight regulation. ${ }^{17} \mathrm{LDL}$ is recruited to the intimal area and damaged endothelium or reactive oxygen species (ROS) stress transforms LDL to oxidized LDL, which is a kind of toxin. ${ }^{18}$ For the initiation of calcification, vSMC apoptosis, followed by infiltration of macrophages triggering local or systemic inflammation in our body, is crucial for vascular calcification, and the release of calcifying matrix vesicles is the first signal for early microcalcification. ${ }^{19}$ These cell deaths provide circulating complexes of phospholipid-rich debris or EVs that serve as nucleating sites for calcium phosphate and crystallization of hydroxyapatite. ${ }^{20}$ Medial SMCs can differentiate into osteochondrogenic or osteoblastic cells. $^{21} 22$ Progression of a calcifying lesion is facilitated by the loss of inhibitors of vascular calcification, such as matrix Gla protein, fetuin-A, osteopontin (OPN), and osteoprotegerin $(\mathrm{OPG}) .^{23}$ Vascular calcification is a process resembling bone formation, for example, the receptor activator of the nuclear factor-kappa B ligand (RANKL)/OPG pathway is the link between osteoporosis and CAC. ${ }^{24}$ OPG is protective against osteoporosis and reduces vascular calcification by RANKL/OPG interaction. ${ }^{25-27}$ Although the exact site where homocysteine plays pivotal part in the genesis of calcified plaque is not quite known, it seems to intervene with several steps in the formation of microcalcification.

There are many clinical risk factors for developing vascular calcification, such as age, gender, and inflammatory status (highly sensitive $\mathrm{C}$ reactive protein, fibrinogen) and comorbidities, such as hypertension, dyslipidemia, hyperphosphatemia, diabetes, and chronic kidney disease. ${ }^{21}$ There are several studies demonstrating that vascular calcification is associated with elevated homocysteine, yet it is not fully understood how an elevated homocysteine level evokes vascular calcifications. Some histological evidence has shown that homocysteine concentration was higher in the calcified plaques than in the non-calcified plaques. ${ }^{28}$ Furthermore, some cellular-level studies show that homocysteine can facilitate osteogenic cell differentiation (conversion of vSMCs to incorporate an osteoblastic feature), which can be proved by calcium deposition, alkaline phosphatase (ALP) activity, and the family of bone-related proteins. ${ }^{7}$ Clinical studies have shown the same outcomes that homocysteine is associated with vascular calcification, and there is a positive correlation between its elevated level and the progression of calcification. ${ }^{29}$

Elevated homocysteine alters the endothelial integrity and tone by endothelial damage, vSMC proliferation, increased ROS, and reduced glutathione peroxidase activity, eventually leading to vascular inflammation. ${ }^{30}$ There are several in vitro studies about homocysteine evoking vascular inflammation by reducing the nitrogen monoxide and increasing ROS in endothelial cells. ${ }^{31}$ The physiological level of homocysteine induces oxidation of LDL, and an elevated homocysteine level leads to the production of homocysteine thioacetone, a highly reactive molecule. ${ }^{32}$ An increased homocysteine level accumulates lipid deposits and oxidized LDL in the vessel, triggering the depositing of atherosclerotic plaque and vascular inflammatory pathway. ${ }^{33}$ In short, a high level of serum homocysteine is associated with endothelial damage. Homocysteine induces calcification by modulating bone-related markers, such as OPN and OPG. ${ }^{3435}$ Also, homocysteine promotes the proliferation of vSMC, especially calcifying vSMC, and increases calcium and phosphorous uptake rates in vSMCs, which are associated with elevated ALP activity. ${ }^{36}$ Furthermore, a high level of homocysteine makes the vessels thicken and stiffen by altering the vascular coagulation and thrombosis pathway and stimulating the vSMCs to proliferate. ${ }^{37}$ As mentioned above, debris of apoptosis produces a lot of lipid core and circulating matrix vesicles, and these serve as a calcium phosphate nucleating core. This process is triggered and accelerated in the increased homocysteine state, which is how elevated serum homocysteine level is involved in vascular calcifications. Similar clinical studies have shown that increased serum homocysteine is correlated to increased

Table 4 AUC and its cut-off value for serum homocysteine according to increase in coronary-artery calcification volume score (CVS)

\begin{tabular}{lllll}
\hline AUC $(95 \% \mathrm{Cl})$ & Homocysteine & Sensitivity & 1-Specificity & P value \\
\hline $0.569(0.512$ to 0.625$)$ & 9.45 & 0.711 & 0.578 & 0.015 \\
\hline
\end{tabular}

Homocysteine represents serum concentration correspondent to the cut-off value.

AUC, area under the curve. 
CAC. Kullo et al showed that serum homocysteine is associated with CAC independent of other CVD risk factors, being possible as a clinical CVS risk marker. ${ }^{8}$ In the MultiEthnic Study of Atherosclerosis cohort, homocysteine was associated with the presence of CAC and the progression of CAC. ${ }^{38}$ The study concluded that elevated homocysteine is a risk factor for severe vascular calcification progression. Bearing in mind that homocysteine induces vascular inflammation, we assumed that there would be a trigger point where vascular calcification accelerates. Our result is similar to the cross-sectional study of Kim et al that looked into the relationship of homocysteine to CAC in Korean men, but their mean homocysteine level was higher than that of our study and included diabetes and current smokers. ${ }^{39}$ Other studies on CAC presented the valuable CAC to be over 400 calculated by the Agatston method. ${ }^{5}$ However, this CAC level is for those who already have cardiac symptoms or who have existing coronary disease requiring secondary prevention and treatment measures, such as medication and invasive coronary angiography. For primary prevention, the lower point of CAC should be clarified. Based on our findings, we suggest there is a point of homocysteine that is the threshold value of the presence of macrocalcification in the coronary artery for diagnosing asymptomatic subclinical coronary disease. For those whose homocysteine level is over $9.45 \mu \mathrm{mol} / \mathrm{L}$ without chronic illness, there is plausible vascular inflammation present, and coronary CT scan is recommended to evaluate a possible cardiovascular problem.

This study has several limitations. First, the AUC is relatively low (0.569). Even though AUC was not high enough, the main focus of the current study was to determine the cut-off value of representing the serum homocysteine concentration in relation to the increase of coronary-artery CVS. In clinics, we frequently observed that serum homocysteine concentrations above $10 \mu \mathrm{mol} / \mathrm{L}$ were significantly associated with increased coronary artery calcification score (CACS) $>0$ as well as abnormal metabolic parameters. Therefore, we conducted the current study to understand the cut-off value of serum homocysteine in relation to the increase of CVS. It is well known that the CACS and CVS are associated with various factors such as age, BMI, calcium, vitamin $\mathrm{D}$ and $\mathrm{K}$ metabolism, smoking, and so on. The CVS, not CACS, was chosen in this study, since the CVS was to represent active growing calcification status, whereas CACS was the passive score to represent the real calcification in coronary artery. In addition, serum homocysteine has been reported to be an inflammatory marker to show the current inflammation in blood vessels and it can be related to the CAC increase, CVS. ${ }^{40-42}$ Considering serum homocysteine itself can be a minor contributor in comparison with other various confounding factors, it is not surprising to see the AUC of 0.569. In addition, there was a tight relationship of serum homocysteine with CVS. Therefore, we concluded that the cut-off value has a significant meaning despite of the low AUC. We believe that the increased serum homocysteine is one of the factors to have a relation with the increased CVS, coronary artery inflammation, and possible development of coronary artery diseases. We understand that the number of study subjects $(n=469)$ in this study may not be enough for fancy AUC. However, we believe that the cut-off value of serum homocysteine above $9.45 \mu \mathrm{mol} / \mathrm{L}$ can be informative for many clinicians trying to prevent coronary diseases and to control heart health. Furthermore, such cut-off value can serve as a point of recommendation to evaluate the CVS or CACS by coronary artery imaging study in a near future, especially in high-risk patients or subjects. Second, the result cannot address the factors that might have affected the homocysteine level. For example, vitamin intake (vitamins $\mathrm{B}_{6}, \mathrm{~B}_{12}$, and folate) and smoking cessation were not considered as factors in this study. Third, well-known risk factors for developing coronary calcification, such as LDL-C, total cholesterol, and systolic hypertension, were not related to CVS. In another study for risk factors for predicting subclinical coronary calcified artery disease, LDL-C alone was positively related to coronary calcification, ${ }^{43}$ because our subjects were relatively healthy, with well-controlled blood pressure and a normal range of lipid profile (mean total cholesterol was $209.2 \mathrm{mg} / \mathrm{dL}$ (SD 35.8)). It is probable that the relatively healthy subjects and small number of subjects in this study lead to no association between metabolic biomarkers and CAC. In case of blood pressure, subjects with high systolic or diastolic blood pressure (>140 or $90 \mathrm{~mm} \mathrm{Hg}$ ) were $8.9 \%$ and $11.5 \%$, respectively. Subjects with high total cholesterol, high triglyceride, high LDL-C, or low high-density lipoprotein were $14.9 \%$, $37.7 \%, 49.8 \%$, and $14.9 \%$, respectively. In addition, it should not be overlooked that the metabolic biomarkers such as blood pressure and cholesterol were obtained from regular health screenings, whereas CVS was the result of chronic exposure of blood vessel inflammation. The regression analysis between CVS and age, BMI, blood pressure, and cholesterol parameters indicates only significance with age (data were not known). Third, our cut-off value of homocysteine cannot be generalized to all populations. CAC scoring has a disparity according to ethnicity, age, and gender; so our cut-off value of homocysteine should be considered valid only for healthy Korean people who had not been diagnosed with hyperlipidemia and diabetes. Nonetheless, this was the first study to clarify the cut-off value of serum homocysteine for predicting the presence of CAC in Korean adults. A further prospective and welldesigned large study should be done.

\section{CONCLUSIONS}

In summary, the findings of this study are that serum homocysteine was associated with coronary-artery CVS; its correlation remained significant even after adjustments for the risk factors of coronary artery disease, such as age, smoking, and hypertension. In addition, the cut-off value of serum homocysteine was $9.45 \mu \mathrm{mol} / \mathrm{L}$ in relation to the presence of the CAC.

Correction notice The order of authors has been corrected since this article was first published.

Contributors Study concept and design: NSJ, BHC, SJ, YNK. Acquisition of data: BHC, NSJ. Analysis and interpretation: SJ, NSJ, YNK, BHC. Drafting of the manuscript: SJ, NSJ.

Funding The authors have not declared a specific grant for this research from any funding agency in the public, commercial or not-for-profit sectors.

Competing interests None declared.

Patient consent for publication Not required. 
Ethics approval The study design was approved by the Institutional Review Board of Ajou University and Bundang CHA Hospital (AJIRB-MEDMDB16-268, CHAMC 2016-10-020).

Provenance and peer review Not commissioned; externally peer reviewed.

Data availability statement All data relevant to the study are included in the article or uploaded as supplementary information.

Open access This is an open access article distributed in accordance with the Creative Commons Attribution Non Commercial (CC BY-NC 4.0) license, which permits others to distribute, remix, adapt, build upon this work noncommercially, and license their derivative works on different terms, provided the original work is properly cited, an indication of whether changes were made, and the use is non-commercial. See: http://creativecommons.org/ licenses/by-nc/4.01.

\section{ORCID iD}

Nam-Seok Joo http://orcid.org/0000-0001-5895-1800

\section{REFERENCES}

1 Han D, O Hartaigh B, Gransar H, et al. Incremental benefit of coronary artery calcium score above traditional risk factors for all-cause mortality in asymptomatic Korean adults. Circ J 2015;79:2445-51.

2 Becker A, Leber A, Becker C, et al. Predictive value of coronary calcifications for future cardiac events in asymptomatic individuals. Am Heart J 2008;155:154-60.

3 McEvoy JW, Blaha MJ, Defilippis AP, et al. Coronary artery calcium progression: an important clinical measurement? A review of published reports. J Am Coll Cardiol 2010;56:1613-22.

4 Budoff MJ, Shaw LJ, Liu ST, et al. Long-Term prognosis associated with coronary calcification: observations from a Registry of 25,253 patients. J Am Coll Cardiol 2007:49:1860-70.

5 Han D, O Hartaigh B, Gransar H, et al. Prevalence and Distribution of Coronary Artery Calcification in Asymptomatic United States and Korean Adults - Cross-Sectional Propensity-Matched Analysis. Circ J 2016;80:2349-55

6 Van Campenhout A, Moran CS, Parr A, et al. Role of homocysteine in aortic calcification and osteogenic cell differentiation. Atherosclerosis 2009:202:557-66.

7 McCully KS. Vascular pathology of homocysteinemia: implications for the pathogenesis of arteriosclerosis. Am J Pathol 1969;56:111-28.

8 Kullo IJ, Li G, Bielak LF, et al. Association of plasma homocysteine with coronary artery calcification in different categories of coronary heart disease risk. Mayo Clin Proc 2006;81:177-82.

9 Wang Y, Osborne MT, Tung B, et al. Imaging cardiovascular calcification. J Am Heart Assoc 2018;7:e008564.

10 Detrano R, Guerci AD, Carr JJ, et al. Coronary calcium as a predictor of coronary events in four racial or ethnic groups. N Eng/ J Med 2008;358:1336-45.

11 Budoff MJ, Hokanson JE, Nasir K, et al. Progression of coronary artery calcium predicts all-cause mortality. JACC Cardiovasc Imaging 2010;3:1229-36.

12 Nasir K, Bittencourt MS, Blaha MJ, et al. Implications of coronary artery calcium testing among statin candidates according to American College of Cardiology/ American heart association cholesterol management guidelines. J Am Coll Cardiol 2015;66:1657-68.

13 New SEP, Aikawa E. Role of extracellular vesicles in de novo mineralization: an additional novel mechanism of cardiovascular calcification. Arterioscler Thromb Vasc Biol 2013;33:1753-8.

14 Zazzeroni L, Faggioli G, Pasquinelli G. Mechanisms of arterial calcification: the role of matrix vesicles. Eur J Vasc Endovasc Surg 2018;55:425-32.

15 Chistiakov DA, Myasoedova VA, Melnichenko AA, et al. Calcifying matrix vesicles and atherosclerosis. Biomed Res Int 2017;2017:1-7.

16 Greenland P, LaBree L, Azen SP, et al. Coronary artery calcium score combined with Framingham score for risk prediction in asymptomatic individuals. JAMA 2004;291:210-5.

17 Schurgers LJ, Akbulut AC, Kaczor DM, et al. Initiation and propagation of vascular calcification is regulated by a concert of Platelet- and smooth muscle cell-derived extracellular vesicles. Front Cardiovasc Med 2018;5:36.
18 Lopes-Virella MF, Baker NL, Hunt KJ, et al. Oxidized LDL immune complexes and coronary artery calcification in type 1 diabetes. Atherosclerosis 2011;214:462-7.

19 Otsuka F, Sakakura K, Yahagi K, et al. Has our understanding of calcification in human coronary atherosclerosis progressed? Arterioscler Thromb Vasc Biol 2014;34:724-36.

20 Kapustin AN, Chatrou MLL, Drozdov I, et al. Vascular smooth muscle cell calcification is mediated by regulated exosome secretion. Circ Res 2015;116:1312-23.

21 Giachelli CM. Vascular calcification mechanisms. J Am Soc Nephrol 2004;15:2959-64.

22 Durham AL, Speer MY, Scatena M, et al. Role of smooth muscle cells in vascular calcification: implications in atherosclerosis and arterial stiffness. Cardiovasc Res 2018;114:590-600.

23 Liu W, Zhang Y, Yu C-M, et al. Current understanding of coronary artery calcification. J Geriatr Cardiol 2015;12:668-75.

24 Byon $\mathrm{CH}$, Chen Y. Molecular mechanisms of vascular calcification in chronic kidney disease: the link between bone and the vasculature. Curr Osteoporos Rep 2015;13:206-15.

25 Bucay N, Sarosi I, Dunstan CR, et al. osteoprotegerin-deficient mice develop early onset osteoporosis and arterial calcification. Genes Dev 1998;12:1260-8

26 Bennett BJ, Scatena M, Kirk EA, et al. Osteoprotegerin inactivation accelerates advanced atherosclerotic lesion progression and calcification in older ApoE-/mice. Arterioscler Thromb Vasc Biol 2006;26:2117-24.

$27 \mathrm{Min} \mathrm{H}$, Morony S, Sarosi I, et al. Osteoprotegerin reverses osteoporosis by inhibiting endosteal osteoclasts and prevents vascular calcification by blocking a process resembling osteoclastogenesis. J Exp Med 2000;192:463-74.

28 Liu T, Lin J, Ju T, et al. Vascular smooth muscle cell differentiation to an osteogenic phenotype involves matrix metalloproteinase- 2 modulation by homocysteine. Mol Cell Biochem 2015;406:139-49.

29 Von Feldt JM, Scalzi LV, Cucchiara AJ, et al. Homocysteine levels and disease duration independently correlate with coronary artery calcification in patients with systemic lupus erythematosus. Arthritis Rheum 2006;54:2220-7.

30 Papatheodorou L, Weiss N. Vascular oxidant stress and inflammation in hyperhomocysteinemia. Antioxid Redox Signal 2007;9:1941-58.

31 Tyagi N, Sedoris KC, Steed M, et al. Mechanisms of homocysteine-induced oxidative stress. Am J Physiol Heart Circ Physiol 2005;289:H2649-56.

32 Jakubowski H, Zhang L, Bardeguez A, et al. Homocysteine thiolactone and protein homocysteinylation in human endothelial cells: implications for atherosclerosis. Circ Res 2000;87:45-51.

33 Lai WKC, Kan MY. Homocysteine-Induced endothelial dysfunction. Ann Nutr Metab 2015;67:1-12.

34 Kwon HM, Hong BK, Kang TS, et al. Expression of osteopontin in calcified coronary atherosclerotic plaques. J Korean Med Sci 2000;15:485-93.

35 Van Campenhout A, Golledge J. Osteoprotegerin, vascular calcification and atherosclerosis. Atherosclerosis 2009;204:321-9.

36 Li J, Chai S, Tang C, et al. Homocysteine potentiates calcification of cultured rat aortic smooth muscle cells. Life Sci 2003;74:451-61.

37 Chen C, Halkos ME, Surowiec SM, et al. Effects of homocysteine on smooth muscle cell proliferation in both cell culture and artery perfusion culture models. J Surg Res 2000;88:26-33.

38 Karger AB, Steffen BT, Nomura SO, et al. Association between homocysteine and vascular calcification incidence, prevalence, and progression in the MESA cohort. J Am Heart Assoc 2020;9:e013934.

39 Kim BJ, Kim BS, Kang JH. Plasma homocysteine and coronary artery calcification in Korean men. Eur J Prev Cardiol 2015;22:478-85.

40 Hokanson JE, MacKenzie T, Kinney G, et al. Evaluating changes in coronary artery calcium: an analytic method that accounts for interscan variability. $A J R$ Am J Roentgenol 2004;182:1327-32.

41 Raggi P, Callister TQ, Shaw LJ. Progression of coronary artery calcium and risk of first myocardial infarction in patients receiving cholesterol-lowering therapy. Arterioscler Thromb Vasc Biol 2004;24:1272-7.

42 Glodny B, Helmel B, Trieb T, et al. A method for calcium quantification by means of $\mathrm{CT}$ coronary angiography using 64-multidetector $\mathrm{CT}$ : very high correlation with Agatston and volume scores. Eur Radiol 2009;19:1661-8.

43 Taylor AJ, Feuerstein I, Wong H, et al. Do conventional risk factors predict subclinical coronary artery disease? Results from the prospective army coronary calcium project. Am Heart J 2001;141:463-8. 


\section{Correction: Cut-off value of serum homocysteine in relation to increase of coronary artery calcification}

Joo N, Jung S, Kim Y, et al. Cut-off value of serum homocysteine in relation to increase of coronary artery calcification. J Investig Med 2021;69:345-50.doi:10. 1136/jim-2020-001478

The order of authors in this article has been corrected since it was first published. The order of authors should be as follows: Susie Jung, Yu-Na Kim, Beom-Hee Choi, Nam-Seok Joo.

\section{(2) \\ OPEN ACCESS}

Open access This is an open access article distributed in accordance with the Creative Commons Attribution Non Commercial (CC BY-NC 4.0) license, which permits others to distribute, remix, adapt, build upon this work non-commercially, and license their derivative works on different terms, provided the original work is properly cited, an indication of whether changes were made, and the use is non-commercial. See: http:// creativecommons.org/licenses/by-nc/4.0/.

(C) American Federation for Medical Research 2022. Re-use permitted under CC BY-NC. No commercial re-use. Published by BMJ.

J Investig Med 2022;70:1325. doi:10.1136/jim-2020-001478corr1

D) Check for updates 